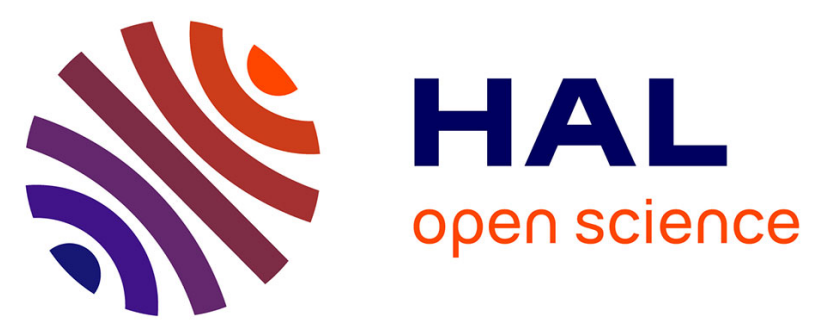

\title{
Impact of Phase-Filtering on Optical Spectral Reshaping with Microring Resonators for Directly-Modulated 4-PAM Signals
}

\author{
Oskars Ozolins, Francesco da Ros, Valentina Cristofori, Xiaodan Pang, \\ Aleksejs Udalcovs, Richard Schatz, Leif Katsuo Oxenløwe, Sergei Popov, \\ Gunnar Jacobsen, Christophe Peucheret
}

\section{To cite this version:}

Oskars Ozolins, Francesco da Ros, Valentina Cristofori, Xiaodan Pang, Aleksejs Udalcovs, et al.. Impact of Phase-Filtering on Optical Spectral Reshaping with Microring Resonators for DirectlyModulated 4-PAM Signals. Conference on Lasers and Electro-Optics (CLEO 2018), May 2018, San Jose, United States. pp.SM2C.5, 10.1364/CLEO_SI.2018.SM2C.5 . hal-01826904

\section{HAL Id: hal-01826904 https://hal.science/hal-01826904}

Submitted on 30 Jun 2018

HAL is a multi-disciplinary open access archive for the deposit and dissemination of scientific research documents, whether they are published or not. The documents may come from teaching and research institutions in France or abroad, or from public or private research centers.
L'archive ouverte pluridisciplinaire HAL, est destinée au dépôt et à la diffusion de documents scientifiques de niveau recherche, publiés ou non, émanant des établissements d'enseignement et de recherche français ou étrangers, des laboratoires publics ou privés. 


\title{
Impact of Phase-Filtering on Optical Spectral Reshaping with Microring Resonators for Directly-Modulated 4-PAM Signals
}

\author{
O. Ozolins ${ }^{1}$, F. Da Ros ${ }^{2}$, V. Cristofori ${ }^{2}$, X. Pang ${ }^{3,1}$, A. Udalcovs ${ }^{1}$, R. Schatz ${ }^{3}$, \\ L.K. Oxenløwe ${ }^{2}$, S. Popov ${ }^{3}$, G. Jacobsen ${ }^{1}$, and C. Peucheret ${ }^{4}$ \\ ${ }^{I}$ Networking and Transmission Laboratory, RISE Acreo AB, Kista, Sweden \\ ${ }^{2}$ DTU Fotonik, Technical University of Denmark, DK-2800 Kongens Lyngby, Denmark \\ ${ }^{3}$ KTH Royal Institute of Technology, Kista, Sweden \\ ${ }^{4}$ Univ Rennes, CNRS, FOTON - UMR 6082, F-22305 Lannion, France \\ Authore-mail address: oskars.ozolins@ri.se
}

\begin{abstract}
We investigate microring resonator (MRRs)-based optical spectral reshaping for directly-modulated 4-PAM signals. The phase-filtering of MRR, and consequent dispersion added to the signal, yields $120 \%$ reach increase compared to the $95 \%$ of amplitude-only filtering.

OCIS codes: (070.2615) Frequency filtering; (200.4650) Optical interconnects
\end{abstract}

\section{Introduction}

The need for high-speed connectivity in datacenter environments is driving a significant effort in researching compact, low-cost and energy efficient solutions [1,2]. One of the proposed solutions relies on the use of directly modulated lasers (DMLs), thus replacing the need for external modulators. This choice, however, introduces the challenge of a limited transmission reach due to low dispersion tolerance and poor modulation extinction ratio (ER). These limitations may be overcome by optical spectral reshaping (OSR) by means of an optical filter, e.g an integrated microring resonator (MRR) [2]. Several demonstrations of OSR using MRRs have been reported for both on-off keying (OOK) [2,3] and 4-pulse amplitude modulation (PAM) [4,5] showing the improvement achieved in terms of reach extension. However, the impact of MRR-based filtering, in terms of the interplay between ER enhancement and added dispersion, is yet unclear. While the MRR amplitude transfer function provides frequencyto-amplitude modulation conversion, enhancing the modulation ER, its phase transfer function may provide additional narrow-band dispersion which could potentially impact the transmission reach.

In this paper we address this key aspect by a detailed numerical analysis of the OSR comparing amplitude-only and complex transfer functions (TFs) of a MRR. We show reach improvements over dispersion-uncompensated standard single-mode fiber (SSMF) links of approximately 95\% thanks to optimized amplitude-only OSR for 20 GBaud 4-PAM signals. The reach is further increased up to $120 \%$ with use of the optimized complex TF.

\section{System under investigation}

Simulations (see setup Fig.1 (a)) for transmission of 20 Gbaud directly-modulated 4-PAM modulation over SSMF were performed in VPItransmissionMaker ${ }^{\mathrm{TM}}[6]$. Two data streams generated from $2^{15}-1$ pseudo random bit sequences with non-return-to-zero (NRZ) line coding were passively combined to create an electrical 4-PAM signal, which was applied to a directly modulated laser (DML). Single-mode laser rate equations using parameters from [7] were used. After the DML, the in-to-through TFs of an MRR were applied, either considering the amplitude-only or the full complex response. The MRR free spectral range (FSR) was set to $60 \mathrm{GHz}$ and its power coupling coefficient $\left(\mathrm{k}_{\mathrm{p}}\right)$ was varied between 0.3 and 0.9 . After photodetection, the signal was low-pass filtered with a $15 \mathrm{GHz} 4^{\text {th }}$ order Bessel filter. Error counting ( $2^{16}$ symbols) was used to calculate the bit-error-ratio (BER).
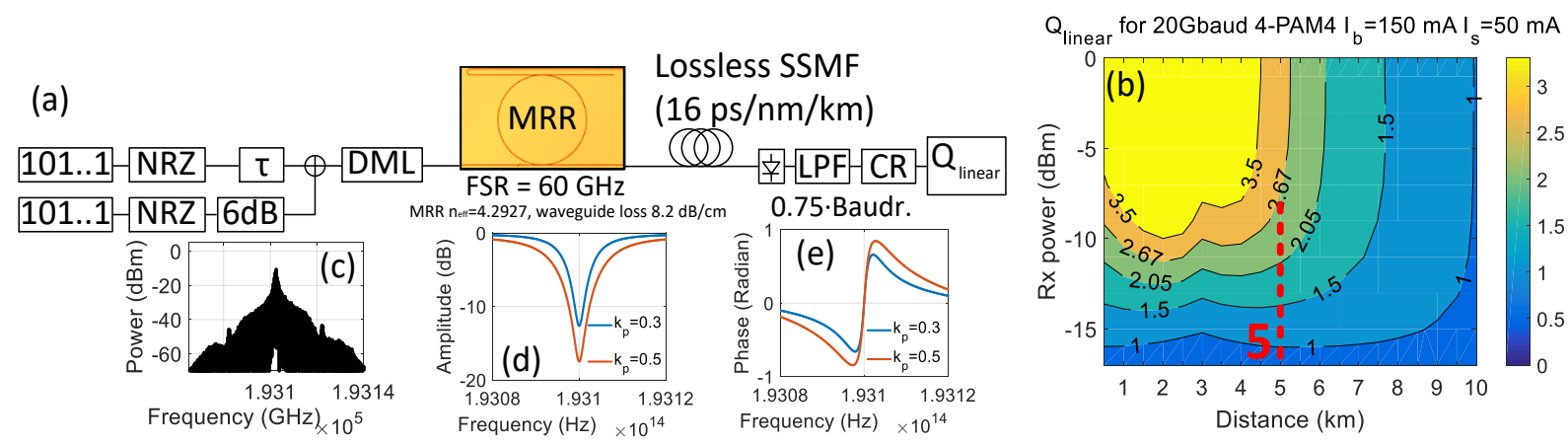

Fig. 1. (a) System under investigation; (b) $\mathrm{Q}_{\text {linear }}$ as a function of received power and transmission distance for 20 Gbaud 4-PAM with directly modulated laser; (c) spectrum for 20 Gbaud 4-PAM; MRR transfer function: (d) amplitude and (e) phase. 
Fig. 1(b) shows the transmission reach without OSR of the 20 Gbaud 4-PAM signal with the DML biased at $150 \mathrm{~mA}$ and with a $50 \mathrm{~mA}$ modulation current swing. These biasing conditions are kept throughout the analysis. The quality factor (in linear scale, $Q_{\text {linear }}$ ) can be calculated from the BER. The transmission reach below the 7\% overhead hard-decision forward error correction (HD-FEC) threshold level of Qlinear $=2.67 \quad\left(B E R=3.8 \times 10^{-3}\right)$ is approximately $5 \mathrm{~km}(0.5 \mathrm{~km}$ step length in simulations). The spectrum of the signal at the DML output is reported in Fig. 1(c) together with MRR transfer functions with $\mathrm{k}_{\mathrm{p}}=0.3$ and 0.5 in Fig. 1(d) and (e), respectively.

\section{Results and discussions}

Detailed simulations were performed to investigate whether the phase transfer function of the MRR used for OSR may provide additional reach increase for the directly-modulated 4-PAM signal through partial dispersion compensation. The OSR parameters, i.e. detuning of the MRR resonance from the signal central frequency and MRR power coupling coefficient $\left(\mathrm{k}_{\mathrm{p}}\right)$, were optimized at a fixed MRR FSR of $60 \mathrm{GHz}$ and for $5 \mathrm{~km}$ transmission, corresponding to the DML transmission reach without OSR. The optimization was performed for both amplitudeonly and complex MRR TFs. From Fig. 2(a) it is found that the highest signal quality $\left(\mathrm{Q}_{\text {linear }}=3.6\right)$ is achieved with $\mathrm{k}_{\mathrm{p}}=0.5$ and a detuning of $-6.7 \mathrm{GHz}$. With these optimized parameters, the transmission reach was investigated, as shown in Fig. 2(b). With amplitude-only OSR, the transmission reach increases to $9.5 \mathrm{~km}$. The optimum frequency detuning was also checked, and it is the same for highest signal quality as in Fig.2 (a). The improvement is attributed to the frequency-to-amplitude modulation conversion that enhances the modulation ER. The same procedure (optimization of OSR and transmission reach analysis) is then repeated considering the full complex TF of the MRR. From Fig. 2(c) the highest $Q_{\text {linear }}=3.65$ with $\mathrm{k}_{\mathrm{p}}$ of 0.3 and a detuning of $-3.3 \mathrm{GHz}$ is found. Fig. 2(d) shows a transmission reach increase to $11 \mathrm{~km}$. This additional reach is attributed to narrow-band dispersion introduced by the complex TF of the MRR.

(a)

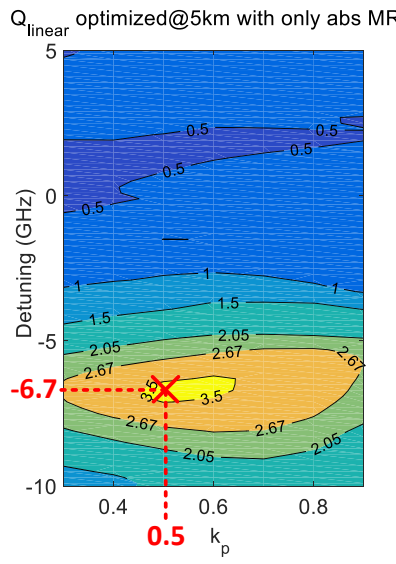

(b)

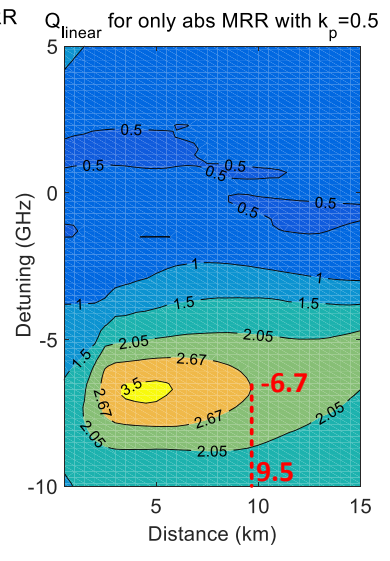

(c)

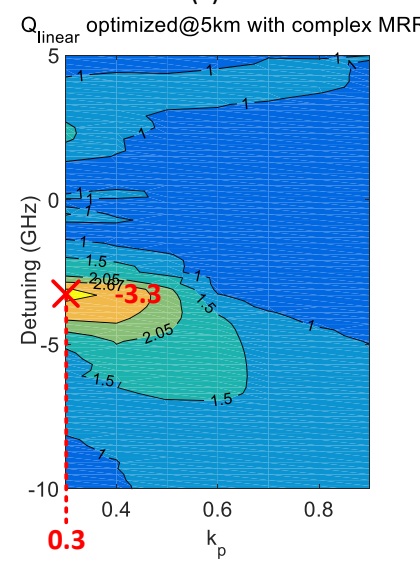

(d)

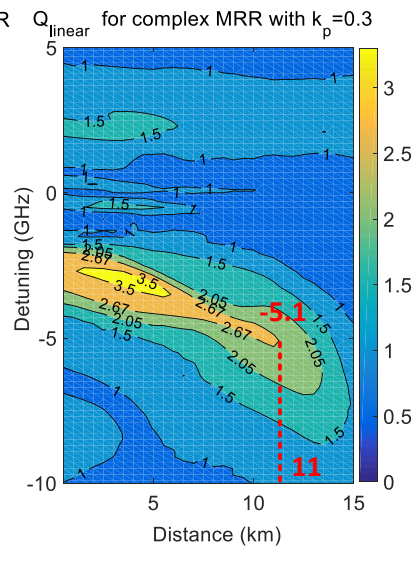

Fig. 2. (a) Qlinear 0 optimization for 20 Gbaud directly-modulated 4-PAM at $5 \mathrm{~km}$ distance with amplitude-only TF of MRR; (b) transmission reach increase with optimized amplitude-only TF of MRR; (c) Qlinear optimization at $5 \mathrm{~km}$ distance with complex TF of MRR; (d) transmission reach increase with optimized complex TF of MRR.

\section{Conclusions}

The transmission reach enhancement is numerically demonstrated for directly-modulated 4-PAM signals using a microring resonator-based optical spectral reshaping. The contribution of the MRR phase transfer function is investigated, showing a further reach increase compared to amplitude-only filtering.

\section{Acknowledgement}

This work was supported by the Vetenskapsrädet grant no. 2016-04510 PHASE, the Swedish SRA ICT-The Next Generation project SCENE and EC Seventh Framework Program (grant no. 619626 SEQUOIA).

\section{References}

[1] O. Ozolins et al., "100 Gbaud 4PAM link for high speed optical interconnects," in ECOC, Gothenburg, Sweden, 2017, paper P2.SC5.6.

[2] A. Shen, et al. "Integrated hybrid III-V/SOI directly modulated DFB laser and ring ...," IEEE Photon. Technol. Lett. 29, 1424-1426 (2017)

[3] V. Cristofori, et al. "Direct modulation of a hybrid III-V/Si DFB laser with MRR ...," in ECOC, Düsseldorf, 2016, paper Th.2.P2.SC4.42.

[4] C. Yang, et al. "IM/DD-based 112-Gb/s/lambda PAM-4 transmission using 18-Gbps DML," IEEE Photon. J. 8, 1-7 (2016).

[5] F. Da Ros, et al. "4-PAM dispersion-uncompensated transmission with micro-ring ...," in CLEO, San Jose, USA, 2017, paper STu1M.5.

[6] www.vpiphotonics.com

[7] Y. An, et al. "Advanced Functionalities for Highly Reliable Optical Networks," Ph.D. thesis, DTU, 2013, Kgs. Lyngby. 